\title{
Pomelo leaves extract as a green corrosion inhibitor for carbon steel in $0.5 \mathrm{M} \mathrm{HCl}$
}

\author{
T.R. Ali, T.A. Salman ${ }^{*} *$ and M.S. Shihab \\ Department of Chemistry, College of Science, Al-Nahrain University, P.O.Box: (64055) \\ Jadriah, Baghdad, Iraq \\ *E-mail:_dr.tag_s@yahoo.com
}

\begin{abstract}
The current work presents a simple, low-cost, and eco-friendly method for carbon steel corrosion retardation in $0.5 \mathrm{M} \mathrm{HCl}$ in a temperature range of $293-313 \mathrm{~K}$. The pomelo plant, which is widespread all over the world, is regarded as a rich source of phytochemical compounds. The maceration method was adopted for pomelo leaf extraction (PLE) and $n$ hexane was used as a solvent (HPLE). The extract components were identified using Gas Chromatography-Mass Spectroscopy (GC-MS) and Fourier transform infrared spectroscopy (FTIR). These characterization methods confirm that HPLE is a rich source of phytochemicals such as alcohols, esters, ethers, alkenes, and ketones. The corrosion investigation was accomplished by electrochemical measurements and scanning electron microscopy (SEM). Potentiodynamic polarization curves for different inhibitor concentrations $(0,25,50,75$, and $100 \mathrm{ppm}$ ) showed that HPLE behaves as a mixed type inhibitor with a maximal inhibition efficiency of about $82 \%$ at $100 \mathrm{ppm}$. The metal surface study was carried out by scanning electron microscopy (SEM) and Energy Dispersive X-ray spectroscopy (EDX). The data obtained from SEM and EDX data are compatible with those obtained from the electrochemical experiments. Metal surface studies proved the presence of a protective film that is constructed by adsorption of inhibitor molecules on the metal surface. Thermodynamic adsorption isotherm calculations show that the adsorption of HPLE on the mild steel surface obeys the Langmuir adsorption isotherm.
\end{abstract}

Received: May 27, 2021. Published: December 16, 2021

doi: $10.17675 / 2305-6894-2021-10-4-23$

Keywords: corrosion, carbon steel, Pomelo, polarization, GC-MS, $\mathrm{HCl}$.

\section{Introduction}

Carbon steel (CS) alloys consist fundamentally from iron and carbon with trace additives of other chemical elements. These alloys are widely used for several aspects of life owing to their attractive properties such as good electrical conductance, heat transfer capability, good magnetic properties, and soft texture. Corrosion of CS leads to wastage of most of its properties, which causes a great disadvantage.

In general, a corrosion process can be defined as a chemical or electrochemical reaction between matter (usually metals or alloys) and their environments, causing destruction of their properties. So the corrosion processes are divided into two types according to the 
environment: chemical corrosion takes place when the metal corrodes in a non-electrolyte environment, such as metal oxidation in hot air, while electrochemical corrosion occurs in an electrolyte solution accompanied by charge transfer across the metal/solution interface [1].

In agreement with the thermodynamic laws, metals tend to access the oxidized state and return to the ore form, which represents a lower energy state. Therefore, the corrosion phenomenon is a spontaneous and irreversible process, Equation 1.

$$
\mathrm{M}^{0} \rightarrow \mathrm{M}^{+n}+n e^{-}
$$

In conjunction with release of electrons from the metal (oxidation process or anodic reaction), electron consumption takes place from the other side (reduction process or cathodic reaction). In an acid environment, the released electrons are captured by protons $\left(\mathrm{H}^{+}\right)$, so the cathodic reaction occurs as shown in Equation 2:

$$
2 \mathrm{H}^{+}+2 e^{-} \rightarrow \mathrm{H}_{2}
$$

In an alkaline or neutral environment, the cathodic reaction occurs by oxygen reduction as shown in Equation 3:

$$
\mathrm{O}_{2}+4 e^{-}+2 \mathrm{H}_{2} \mathrm{O} \rightarrow 4 \mathrm{OH}^{-}
$$

Both reactions (oxidation and reduction) occur on the metal surface at the same rate to ensure that the net current is equal to zero [2]. Since the $40 \mathrm{~s}$ of the past century, the issue of metal corrosion has received considerable interest from researchers because it is the largest destruction factor of equipment. In order to minimize corrosion effects, several trends with different methods have been adopted for prevention or reduction of corrosion processes, such as:

- electrochemical protection methods, such as cathodic or anodic protection;

- amelioration of the nature of metals by modifying the additives in such a way as to increase the corrosion resistance;

- building a protective layer on the surface of a metal or alloy;

- modification of the corrosive environment toward a non-aggressive state by addition of a small amount of a chemical substance, the so-called corrosion inhibitor.

Corrosion inhibition is the most widely used anti-corrosion method among such methods because of its simplicity, economic advantage, and effectiveness [3]. Green corrosion inhibitors are superior to synthetic organic inhibitors because they are ecofriendly, biodegradable, cheap, renewable, and readily available [3-5]. The pomelo plant belongs to the citrus family, which has evergreen leaves and is regarded as a rich source of phytochemicals $[6,7]$.

In this work, pomelo leaves were extracted by the maceration method with n-hexane as the solvent. Subsequently, this extract was examined as a corrosion inhibitor for carbon steel 
in acid media using the potentiodynamic polarization method and a scanning electron microscope (SEM).

\section{Experimental}

\section{Specimen preparation}

The chemical components in weight percentage (wt.\%) in a commercial rectangular plate of carbon steel were determined to be as follows: $\mathrm{C}=0.370 \%, \mathrm{Si}=0.230 \%, \mathrm{~S}=0.014 \%$, $\mathrm{Mn}=0.670 \%, \mathrm{Cu}=0.160 \%, \mathrm{Ni}=0.059 \%, \mathrm{Ti}=0.013 \%, \mathrm{Co}=0.009 \%, \mathrm{Cr}=0.078 \%$ and the remainder iron $(\mathrm{Fe})$. Afterward, the steel plate was segmented into circular specimens with dimensions of $\left(2 \times 20 \mathrm{~mm}^{2}\right)$ and they were polished with emery papers $180,320,1000$, 2500, and 4000. Subsequently, the polished specimens were degreased with ethanol and etched with acetone, then washed with distilled water and left to dry at room temperature.

\section{Solution preparation}

$1 \mathrm{~L}$ of $0.5 \mathrm{M} \mathrm{HCl}$ to be used as the corrosive solution was prepared by adding $41.75 \mathrm{ml}$ of $36 \% \mathrm{HCl}(11.975 \mathrm{M})$ to the appropriate volume of distilled water.

\section{Inhibitor preparation}

Pomelo leaves were collected from the orchards of Diyala Governorate, specifically from Baquba city, and afterward extracted by n-hexane through the following steps:

- the pomelo leaves were washed by tap water in order to remove all dust and other impurities and left for about $72 \mathrm{~h}$ to dry under the sun, thereafter ground by an electric grinder;

- twenty grams of PL powder were macerated in $125 \mathrm{ml}$ of n-hexane and refluxed with stirring for about $72 \mathrm{~h}$ at $40^{\circ} \mathrm{C}$. Then, the mixture was filtrated through Whatman filter paper and the solvent was evaporated at $40^{\circ} \mathrm{C}$, then stored at $4^{\circ} \mathrm{C}$ for the subsequent steps;

- solutions $(25,50,75$, and 100 ppm of HPLE) were prepared by dissolving the appropriate quantity in $20 \mathrm{ml}$ of DMSO, then decanting into $1 \mathrm{~L}$ of $0.5 \mathrm{M} \mathrm{HCl}$.

\section{Gas Chromatography - Mass Spectroscopy (GC-MS) measurement}

The chemical components of HPLE were identified by the GC-MS technique, where a computerized control apparatus (QP 2010 Plus SHIMADZU) was used. The analysis process started with the injection of $2 \mu \mathrm{l}$ of HPLE using a micro syringe at $70 \mathrm{eV}$ and helium gas as a carrier. After 30 min (the run time), the data of the unknown sample was compared with the database library.

\section{Fourier Infrared Spectroscopy}

Functional groups that exist in HPLE were identified through FTIR spectroscopy within the spectral range of $4000-500 \mathrm{~cm}^{-1}$ using a Shimadzu IR Affinity 1 (Japan) spectrometer. 


\section{Electrochemical polarization measurement}

The ability of HPLE to provide corrosion inhibition was estimated by the potentiodynamic polarization method. In this method, three fundamental parts that were used:

1. Corrosion cell: a flat-bottomed container made of Pyrex glass containing three types of electrodes immersed in the solution of corrosion. The three electrodes are:

- A working electrode (WE) was a circular carbon steel specimen under study with a hole surface area of $1 \mathrm{~cm}$ that permits the solution to contact the metal specimen.

- A saturated calomel electrode (reference) (RE) to measure the working electrode potential.

- A platinum electrode (axillary) to complete the cell circuit.

2. Potentiostat/galvanostat at 200Mlb (2007) Germany apparatus. This device controlled the applied potential on the WE relative to the RE, and measured the current between the WE and the auxiliary electrode.

3. A computer connected to the potentiostat for data processing and recoding all the corrosion parameters.

In the polarization test, the open circuit potential (OCP) is achieved first, where the working electrode is kept for about 15 min to attain a steady state. Secondly, starting from the OCP potential, the polarization test is performed by polarizing the WE in the range of $200 \mathrm{mV}$ at a scan rate of $2 \mathrm{mV} / \mathrm{s}$, and then the electrochemical parameters are recorded.

\section{Scanning electron microscope (SEM)}

The FEI Inspect-S50 apparatus (Japan) was used to study the metal surface morphology and assure the adsorption of inhibitor molecules on it.

\section{Result and Discussion}

Gas Chromatography-Mass Spectrometry (GC-MS)

The GC-MS chromatogram of HPLE exhibits that about eighteen phytochemicals are present in this extract. Comparison of the chemical library with this chromatogram reveals there are many organic compounds with various functional groups in the extract. The presence of heteroatoms, heterocyclic and multiple-bond organic compounds provides a rich electronic density which enhances the interaction with metal orbitals, whereas improving the adsorption on the metal surface [3,8]. The GC-MS chromatogram of HPLE is shown in Figure 1. 


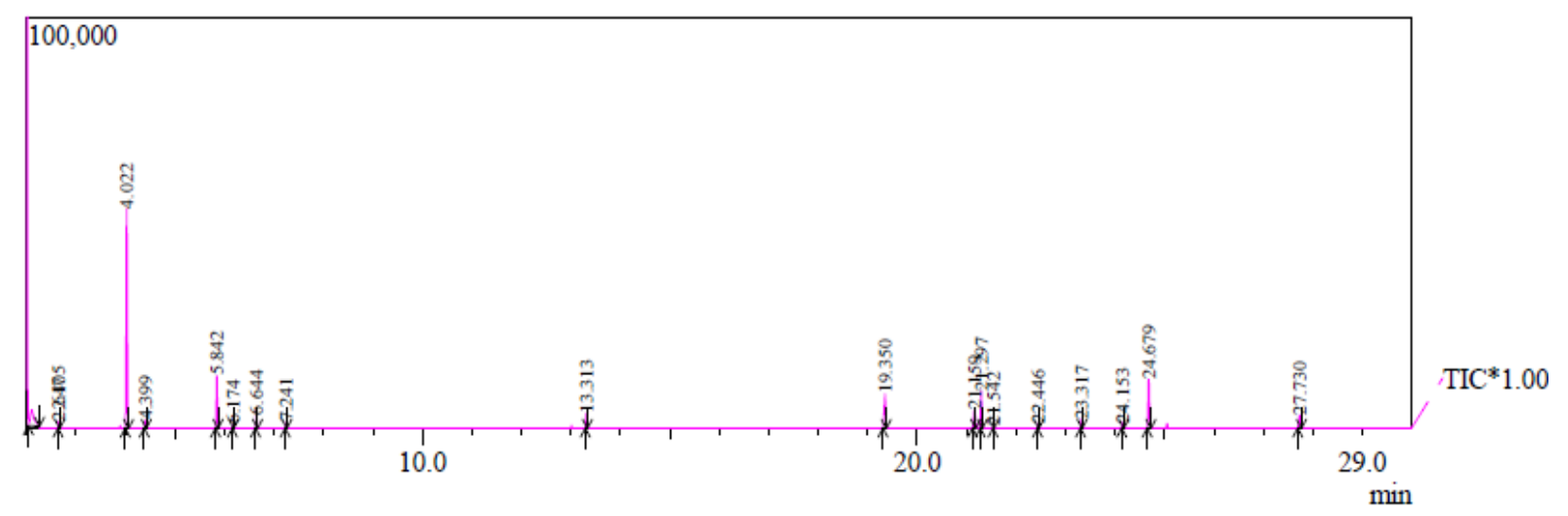

Figure 1. GC-MS Chromatogram of HPLE.

As it is noticeable in Figure 1, the highest intensity among these lines is found for line 3 which belongs to o-xylene, whereas the other lines vary from medium to weak intensity. The nomenclature, retention time, chemical formula, molecular weight and structure of characteristic compounds are demonstrated in Table 1.

Table 1. The major compounds identified in HPLE.

\begin{tabular}{|c|c|c|c|c|c|}
\hline No. & Name of compound & $\begin{array}{c}R T \\
(\min )\end{array}$ & $\begin{array}{l}\text { Chemical } \\
\text { formula }\end{array}$ & $\underset{(\mathrm{g} / \mathrm{mole})}{\mathrm{MW}}$ & Structure \\
\hline 1 & butan-1-ol & 2.108 & $\mathrm{C}_{4} \mathrm{H}_{10} \mathrm{O}$ & 74.12 & \\
\hline 2 & cyclohepta-1,3,5-triene & 2.650 & $\mathrm{C}_{7} \mathrm{H}_{8}$ & 92.14 & \\
\hline 3 & $o$-xylene & 4.025 & $\mathrm{C}_{8} \mathrm{H}_{10}$ & 106.17 & \\
\hline 4 & hepta-2,5-diyn-4-one & 4.400 & $\mathrm{C}_{7} \mathrm{H}_{6} \mathrm{O}$ & 106.12 & \\
\hline 5 & $\begin{array}{l}\text { 6,6-dimethyl-2- } \\
\text { methylenebicyclo[3.1.1]heptane }\end{array}$ & 5.842 & $\mathrm{C}_{10} \mathrm{H}_{16}$ & 136.24 & \\
\hline 6 & $\begin{array}{l}\text { (E)-2-(hydroxyimino)ethyl } \\
\text { acetate }\end{array}$ & 6.175 & $\mathrm{C}_{4} \mathrm{H}_{7} \mathrm{NO}_{3}$ & 117.10 & \\
\hline 7 & 1-(p-tolyl)pentan-1-one & 6.642 & $\mathrm{C}_{12} \mathrm{H}_{16} \mathrm{O}$ & 176.26 & \\
\hline 8 & prop-2-yn-1-ylcyclopentane & 7.242 & $\mathrm{C}_{8} \mathrm{H}_{12}$ & 108.18 & \\
\hline 9 & vinyl methacrylate & 13.317 & $\mathrm{C}_{6} \mathrm{H}_{8} \mathrm{O}_{2}$ & 112.13 & \\
\hline 10 & $\begin{array}{l}\text { methyl 2-hydroxy-2- } \\
\text { methylbutanoate }\end{array}$ & 19.350 & $\mathrm{C}_{6} \mathrm{H}_{12} \mathrm{O}_{3}$ & 132.16 & \\
\hline 11 & 2-(propylsulfonyl)acetonitrile & 21.158 & $\mathrm{C}_{5} \mathrm{H}_{9} \mathrm{NO}_{2} \mathrm{~S}$ & 147.19 & \\
\hline 12 & $\begin{array}{l}\text { 2-(3-(oxiran-2-yl)propyl)-3- } \\
\text { (oxiran-2-ylmethyl)oxirane }\end{array}$ & 21.300 & $\mathrm{C}_{10} \mathrm{H}_{16} \mathrm{O}_{3}$ & 184.24 & \\
\hline
\end{tabular}




\begin{tabular}{ccccc}
\hline No. & Name of compound & $\begin{array}{c}\boldsymbol{R} \boldsymbol{T} \\
(\mathbf{m i n})\end{array}$ & $\begin{array}{c}\text { Chemical } \\
\text { formula }\end{array}$ & $\begin{array}{c}\text { MW } \\
(\mathbf{g} / \mathbf{m o l e})\end{array}$ \\
\hline 13 & allyl butyl oxalate & 21.542 & $\mathrm{C}_{9} \mathrm{H}_{14} \mathrm{O}_{4}$ & 186.21 \\
\hline 14 & butyl propyl oxalate & 22.450 & $\mathrm{C}_{9} \mathrm{H}_{16} \mathrm{O}_{4}$ & 188.22 \\
\hline 15 & $\begin{array}{c}(E) \text {-undec-2-en-4-ol } \\
\text { acetate }\end{array}$ & 23.317 & $\mathrm{C}_{11} \mathrm{H}_{22} \mathrm{O}$ & 170.30 \\
\hline 18 & $\begin{array}{c}(E)-2-(\text { hydroxyimino)ethyl } \\
\text { aceture }\end{array}$ & 24.150 & $\mathrm{C}_{4} \mathrm{H}_{7} \mathrm{NO}_{3}$ & 117.10 \\
\hline $\begin{array}{c}(2 E, 7 E) \text {-4,-trimethylheptane } \\
\text { dien-5-one }\end{array}$ & 24.683 & $\mathrm{C}_{10} \mathrm{H}_{22}$ & 142.29 \\
\hline
\end{tabular}

\section{Fourier Infrared Spectroscopy}

FTIR spectroscopy was used to detect the functional groups that belong to phytochemicals that have been diagnosed previously in GC-MS chromatograms. As it is evident in Figure 2, FTIR analysis gave results that agreed with those obtained by the previous method, where HPLE encompassed an assortment of phytochemicals. The broad peak in the range between $3600-3320 \mathrm{~cm}^{-1}$ is assigned to the alcoholic $\mathrm{OH}$ group, whereas the more intense peak at $1762.28 \mathrm{~cm}^{-1}$ indicates the presence of carbonyl compounds [9]. The other important peaks are listed in Table 2.

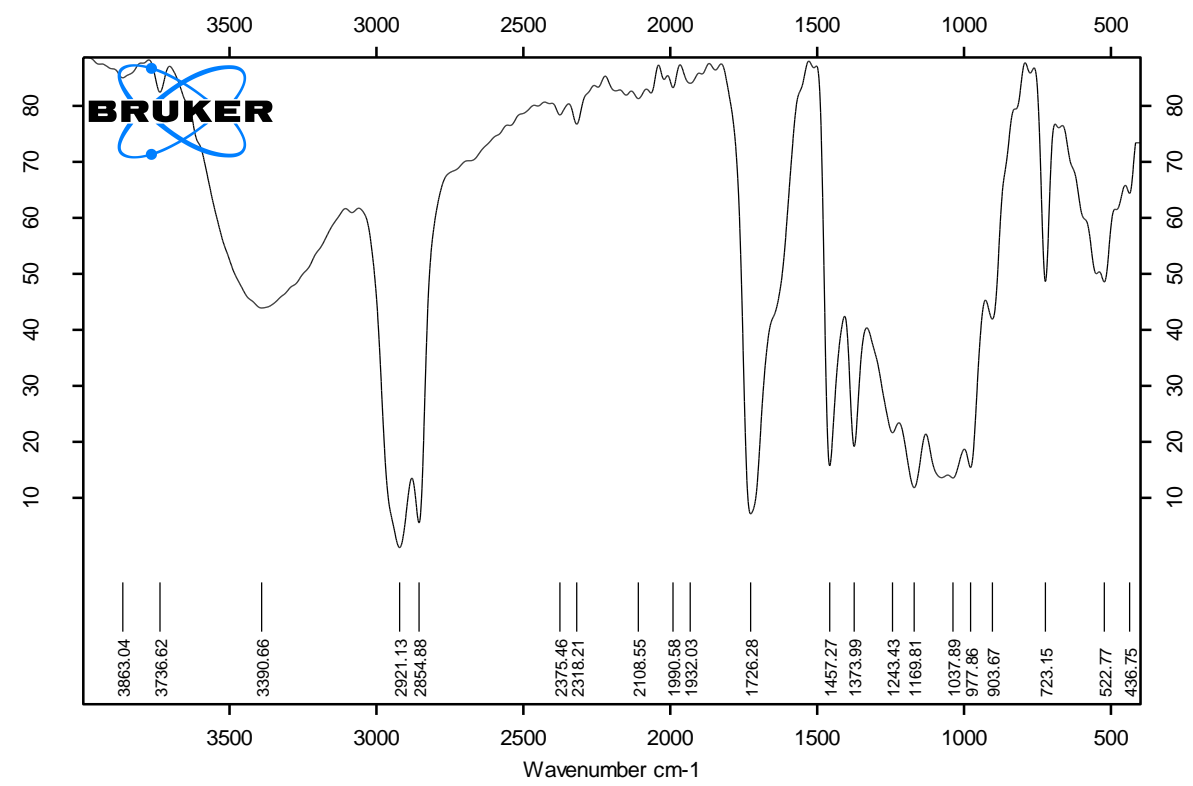

Figure 2. FTIR spectrum of HPLE. 
Of significant functional groups in Figure 2, there is an alcoholic $\mathrm{OH}$ group which is represented by a broad peak in the range from $3736-3200 \mathrm{~cm}^{-1}$. A peak at $1718.24 \mathrm{~cm}^{-1}$ is assigned to the carbonyl group in ester [9]. The other peaks are shown in Table 2.

Table 2. The main bands in HPLE.

\begin{tabular}{cccc}
\hline No. & Peak number, $\mathbf{~ m}^{\mathbf{- 1}}$ & Bond & Group assignment \\
\hline 1 & $3600-3200$ & $\mathrm{O}-\mathrm{H}$ & Alcoholic \\
\hline 3 & 2921.13 & $\mathrm{C}-\mathrm{H}$ & Asymmetric $-\mathrm{CH}_{3}$ \\
\hline 4 & 2854.88 & $\mathrm{C}-\mathrm{H}$ & Symmetric $-\mathrm{CH}_{2}-$ \\
\hline 5 & 1726.28 & $\mathrm{C}=\mathrm{O}$ & Carbonyl compounds \\
\hline 9 & 1451 & $\mathrm{C}-\mathrm{H}$ & Symmetric bending $-\mathrm{CH}_{2}-$ \\
\hline 11 & 1372 & $\mathrm{C}-\mathrm{H}$ & Stretching of C-O bond in ester \\
\hline 12 & 1243.43 & $\mathrm{C}-\mathrm{O}$ & Stretching of O-C bond in ester \\
\hline 14 & 1169.81 & $\mathrm{O}-\mathrm{C}$ & C=N-O stretching in oxime \\
\hline 15 & 977.86 & N-O & Bending O-H (alcohol) \\
\hline
\end{tabular}

\section{Corrosion study}

\section{Potentiodynamic polarization (PDP) curves}

Figure 3 illustrates the polarization curves of potential $E(\mathrm{mV})$ against $\log (i)$ ( $i$ is the current density in $\mu \mathrm{A} / \mathrm{cm}^{2}$ ) for carbon steel in $0.5 \mathrm{M} \mathrm{HCl}$ in the absence and in the presence of various concentrations of the inhibitor in the temperature range of $293-313 \mathrm{~K}$.

As it is seen in these curves, with addition of HPLE, the corrosion potential varies in the active or noble direction. This indicates that HPLE retards both the hydrogen evolution process and metal dissolution. So, the HPLE can be classified as a mixed corrosion inhibitor [10]. The kinetic parameters of corrosion, such as $E_{\text {corr }}, i_{\text {corr }}$, cathodic and anodic Tafel slops, corrosion rate, and penetration rate, that are obtained from the polarization curves are listed in Table 3. 

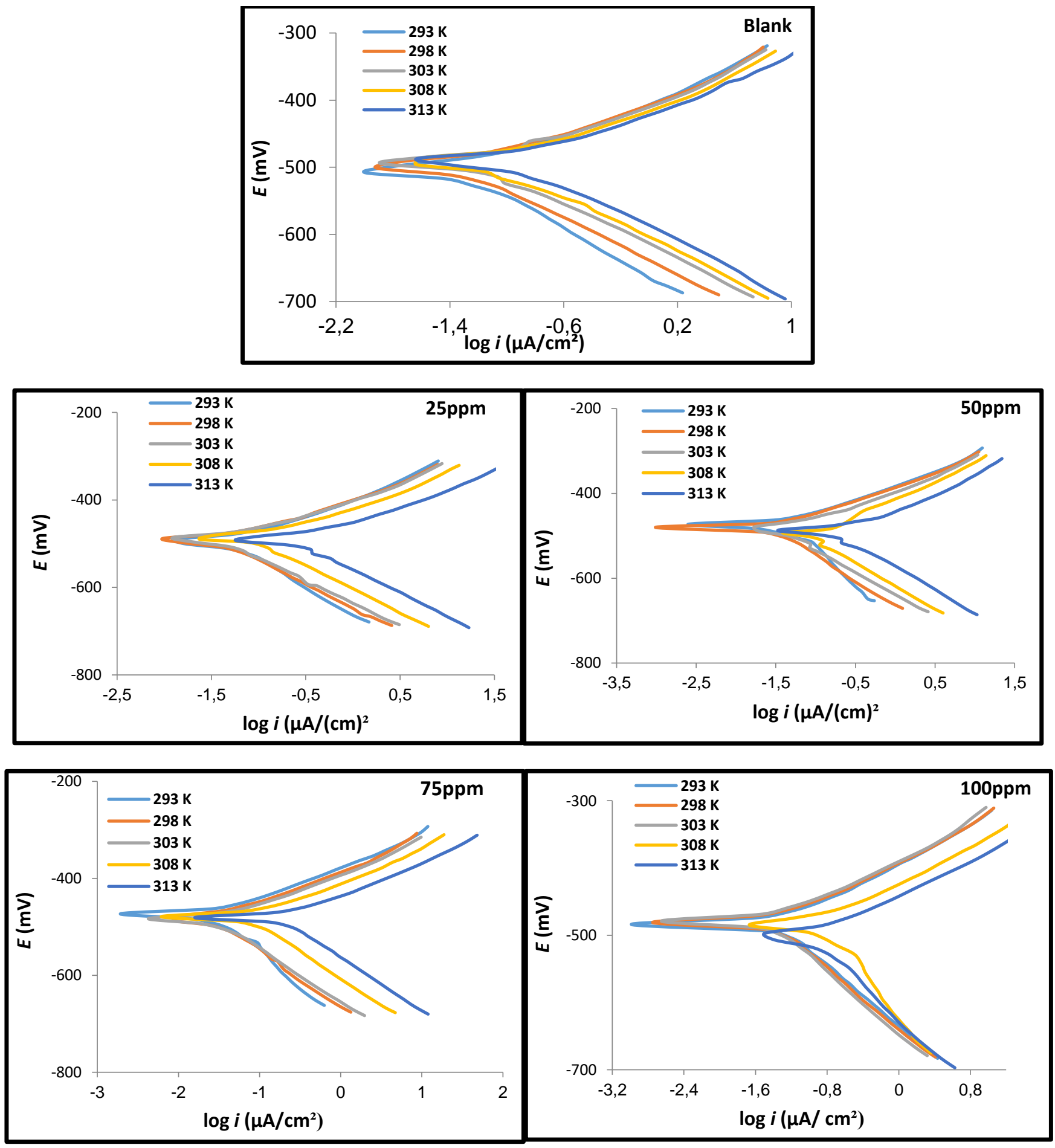

Figure 3. Polarization curves of carbon steel in $0.5 \mathrm{M} \mathrm{HCl}$ without and with different concentrations $(25,50,75,100 \mathrm{ppm})$ of HPLE in the temperature range of $293-313 \mathrm{~K}$. 
Table 3. Corrosion parameters of carbon steel in $0.5 \mathrm{M} \mathrm{HCl}$ without the inhibitor and in the presence of different concentrations $(25,50,75$ and $100 \mathrm{ppm})$ of HPLE in the temperature range of 293-313 K.

\begin{tabular}{|c|c|c|c|c|c|}
\hline Inh. (ppm) & $T(\mathbf{K})$ & $-E_{\operatorname{corr}}(\mathbf{m V})$ & $i_{\text {corr }}\left(\mu \mathrm{A} / \mathrm{cm}^{2}\right)$ & $C R\left(g / \mathrm{m}^{2} \mathbf{d}\right)$ & $P R(\mathrm{~mm} / \mathrm{Y})$ \\
\hline \multirow{5}{*}{0} & 293 & 508 & 42.6 & 10.8 & 0.51 \\
\hline & 298 & 500 & 43.3 & 10.9 & 0.56 \\
\hline & 303 & 494 & 53.2 & 13.3 & 0.615 \\
\hline & 308 & 495 & 64.2 & 16.3 & 0.755 \\
\hline & 313 & 487 & 96.3 & 23.8 & 1.100 \\
\hline \multirow{5}{*}{25} & 293 & 491 & 16.56 & 4.12 & 0.192 \\
\hline & 298 & 489 & 17.11 & 4.25 & 0.197 \\
\hline & 303 & 486 & 21.9 & 5.45 & 0.253 \\
\hline & 308 & 489 & 28.05 & 6.89 & 0.32 \\
\hline & 313 & 493 & 47.8 & 11.88 & 0.55 \\
\hline \multirow{5}{*}{50} & 293 & 473 & 13.07 & 3.25 & 0.151 \\
\hline & 298 & 479 & 14.9 & 3.7 & 0.172 \\
\hline & 303 & 479 & 19.01 & 4.73 & 0.22 \\
\hline & 308 & 492 & 24.51 & 6.1 & 0.283 \\
\hline & 313 & 500 & 43.6 & 10.84 & 0.5 \\
\hline \multirow{5}{*}{75} & 293 & 473 & 8.6 & 2.14 & 0.1 \\
\hline & 298 & 486 & 10.7 & 2.7 & 0.125 \\
\hline & 303 & 483 & 13.51 & 3.36 & 0.156 \\
\hline & 308 & 484 & 18.92 & 4.7 & 0.22 \\
\hline & 303 & 489 & 36.4 & 9.1 & 0.422 \\
\hline \multirow{5}{*}{100} & 293 & 472 & 3.2 & 0.8 & 0.037 \\
\hline & 298 & 479 & 5.5 & 1.4 & 0.065 \\
\hline & 303 & 480 & 8.75 & 2.2 & 0.1 \\
\hline & 308 & 481 & 13.98 & 3.5 & 0.16 \\
\hline & 313 & 484 & 27.3 & 6.8 & 0.32 \\
\hline
\end{tabular}

As it is noticeable in the above table, at certain inhibitor concentrations the inhibition efficiency decreases, the electrochemical impedance of the metal decreases, the corrosion potential shifts to more negative values, and the corrosion rate increases. In contrast, as 
inhibitor concentration increases at certain temperatures, the corrosion potential shifts in the noble direction and the corrosion rate decreases [11, 12].

\section{Effect of temperature}

The temperature effects on carbon steel corrosion in the range of 293-313 K was studied in the absence and in the presence of different HPLE concentrations. Throughout this study, the kinetic parameters of corrosion were calculated though Arrhenius Equation 4.

$$
\log i_{\text {corr }}=\frac{-E_{\mathrm{a}}}{R T}+\log A
$$

Where, $i_{\text {corr }}$ is the corrosion current, $E_{\mathrm{a}}$ is the activation energy of the corrosion process, $R$ is the universal gas constant $(8.314 \mathrm{~J} / \mathrm{mol} \cdot \mathrm{K}), T$ is the absolute temperature $(\mathrm{K})$, and $A$ is the preexponential factor [12]. The slope of the straight line that arises by plotting $\log (i)$ against $1 / T$ represents the fraction of $\left(E_{\mathrm{a}} / 2.303 R\right)$, while the intercept of the straight lines with the $y$ axis is equal to $\log (A)$. From this diagram, the activation energy $E_{\mathrm{a}}$ and the preexponential factor were calculated and listed in Table 4. As seen from the activation energy values shown in Table 4, it increases with an increase in the inhibitor concentration, which is evidence of the corrosion process inhibition. The protective film formed upon adsorption of inhibitor molecules on the metal surface could increase the energy gap $\left(E_{\mathrm{a}}\right)$ between the reactant and the activated complex that exists in the pathway of corrosion products formation, consequently the corrosion process is hindered [13].

The enthalpy of activation $\Delta H_{\mathrm{a}}$ and the entropy of activation $\Delta S_{\mathrm{a}}$ could be calculated by application of an alternative formula of the Arrhenius equation:

$$
i_{\text {corr }}=\left(\frac{R T}{N h}\right) \cdot \exp \left(\frac{\Delta S_{\mathrm{a}}}{R}\right) \cdot \exp \left(\frac{-\Delta H_{\mathrm{a}}}{R T}\right)
$$

Where $N$ is Avogadro's number and $h$ is Planck constant $\left(\mathrm{h}=6.626 \cdot 10^{-34} \mathrm{~J} \cdot \mathrm{s}\right)$. The last formula of Arrhenius equation can be rewritten as the equation below [13]:

$$
\log \left(\frac{i_{\text {corr }}}{T}\right)=\ln \left(\frac{R}{N h}\right)+\left(\frac{\Delta S_{\mathrm{a}}}{R}\right)-\left(\frac{\Delta H_{\mathrm{a}}}{R T}\right)
$$

By plotting $\log \left(i_{\text {corr }} / T\right)$ against $1 / T$ (as seen in Figure 5), the enthalpy of activation $\Delta H_{\mathrm{a}}$ and entropy of activation $\Delta S_{\mathrm{a}}$ can be calculated [14]. 


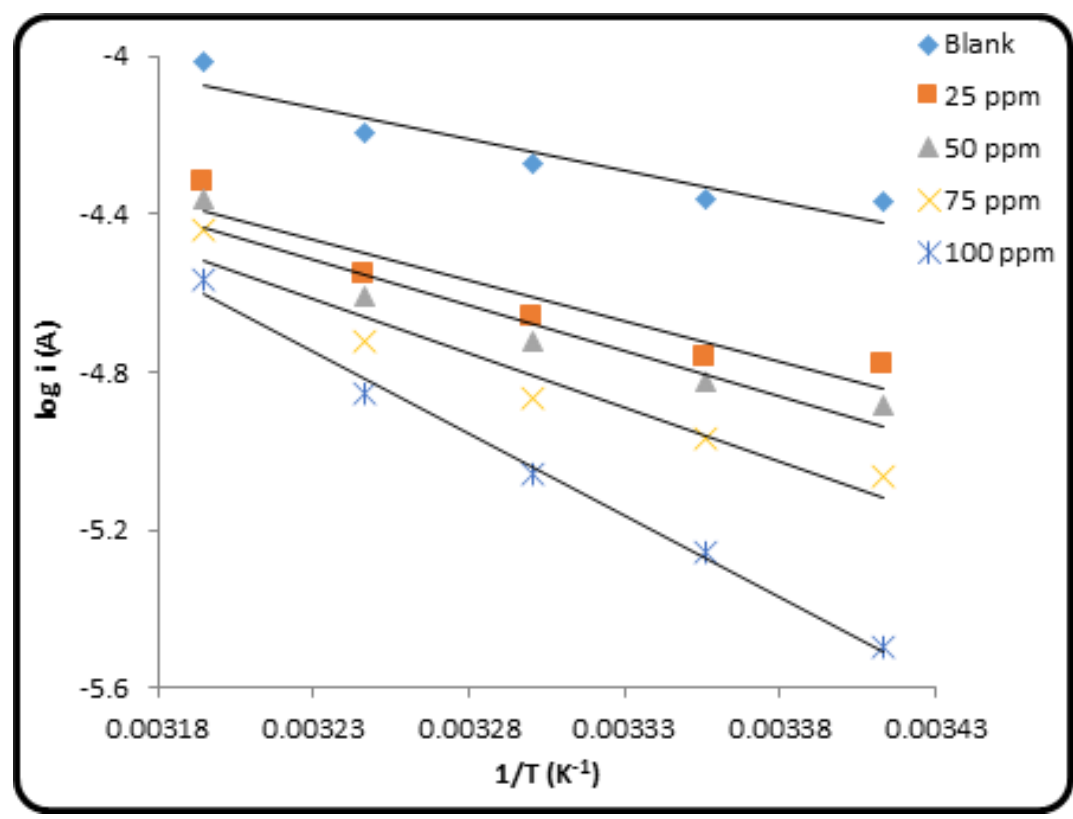

Figure 4. Arrhenius plot of $\log i_{\text {corr }} v s .1 / T$ for carbon steel corrosion in $0.5 \mathrm{M} \mathrm{HCl}$ in the presence and in the absence of different concentrations (25, 50, 75 and $100 \mathrm{ppm})$ of HPLE in the temperature range of $293-313 \mathrm{~K}$.

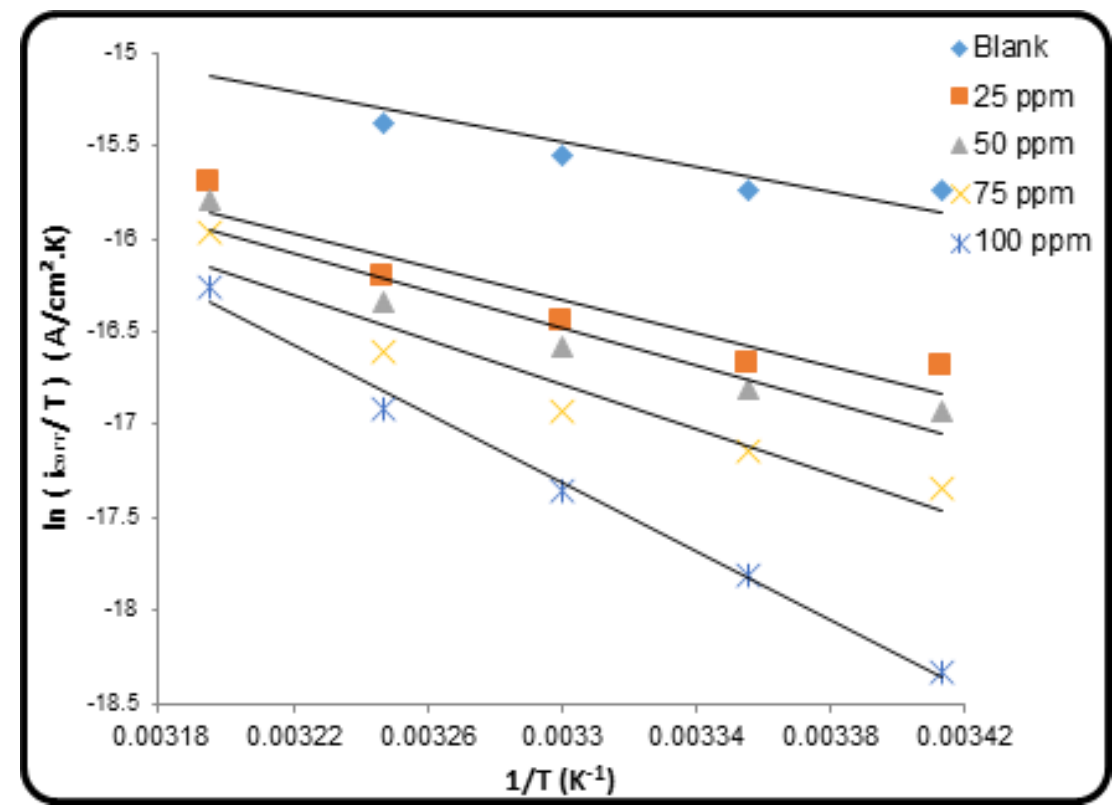

Figure 5. Arrhenius plot of $\log \left(i_{\text {corr }} / T\right) v s$. $(1 / T)$ for carbon steel corrosion in $0.5 \mathrm{M} \mathrm{HCl}$ in the presence and in the absence of different concentrations $(25,50,75$ and $100 \mathrm{ppm})$ of HPLE in the temperature range of $293-313 \mathrm{~K}$.

The activation enthalpy and entropy were calculated and listed in Table 4. Obviously, as it is seen in this table, the activation enthalpy is endothermic and it increases as the inhibitor concentration increases, which delays the corrosion process. Additionally, there is an increase in activation entropy with an increase in inhibitor concentration, which means an increase in irregularity. It is worthwhile to note that the regularity (entropy decrease) 
conforms to the transformation of reactants to activated complexes in the rust formation pathway. Where the activated complex exemplifies the associated state more than the dissociated state, consequently, the increase in entropy refers to the waning of the corrosion process [15].

Table 4. Arrhenius parameters for carbon steel corrosion in $0.5 \mathrm{M} \mathrm{HCl}$ with and without different concentrations of HPLE in the temperature range of 293-313 K.

\begin{tabular}{|c|c|c|c|c|}
\hline Inh. (ppm) & $E_{\mathrm{a}}\left(\mathbf{k J} \cdot \mathbf{m o l}^{-\mathbf{1}}\right)$ & $A\left(\right.$ molecules $\left.\cdot \mathrm{cm}^{-2} \cdot \mathrm{s}^{-1}\right)$ & $\Delta H_{\mathrm{a}}\left(\mathbf{k J} \cdot \mathrm{mol}^{-\mathbf{1}}\right)$ & $-\Delta H_{\mathbf{a}}(\mathrm{J} / \mathbf{K} \cdot \mathbf{m o l})$ \\
\hline 0 & 13 & $6.3 \cdot 10^{23}$ & 28 & 233 \\
\hline 25 & 17 & $1.3 \cdot 10^{24}$ & 37 & 202 \\
\hline 50 & 19 & $1.8 \cdot 10^{24}$ & 42 & 197 \\
\hline 75 & 23 & $2.6 \cdot 10^{24}$ & 50 & 172 \\
\hline 100 & 35 & $5 \cdot 10^{24}$ & 77 & 87 \\
\hline
\end{tabular}

Inhibition efficiency (\%E) and surface coverage $(\theta)$

The inhibition efficiency (\%E) of HPLE in $0.5 \mathrm{M} \mathrm{HCl}$ solution was studied by application of Equation 7:

$$
\% E=\left[1-\frac{i}{i^{0}}\right] \cdot 100
$$

Where $i$ and $i^{0}$ are the corrosion current densities in the presence and absence of HPLE, respectively [14]. The surface coverage $(\theta)$ is calculated by the relationship below $[15,16]$. The inhibition efficiency and surface coverage (for different inhibitor concentrations) are listed in Table 5.

$$
\theta=\left[1-\frac{i}{i^{0}}\right]
$$

Table 5. Inhibition efficiency $\% E$ and surface coverage $\theta$ of HPLE at a different concentration in the temperature range of $293-313 \mathrm{~K}$ in $0.5 \mathrm{M} \mathrm{HCl}$.

\begin{tabular}{ccccccccc}
\hline \multirow{T}{*}{$\boldsymbol{T}(\mathbf{K})$} & \multicolumn{2}{c}{$\mathbf{2 5} \mathbf{~ p p m}$} & \multicolumn{2}{c}{$\mathbf{5 0} \mathbf{~ p p m}$} & \multicolumn{2}{c}{$\mathbf{7 5} \mathbf{~ p m}$} & \multicolumn{2}{c}{$\mathbf{1 0 0} \mathbf{~ p p m}$} \\
\cline { 2 - 8 } & $\boldsymbol{\%} \boldsymbol{E}$ & $\boldsymbol{\theta}$ & $\boldsymbol{\%} \boldsymbol{E}$ & $\boldsymbol{\theta}$ & $\boldsymbol{\%} \boldsymbol{E}$ & $\boldsymbol{\theta}$ & $\boldsymbol{\%} \boldsymbol{E}$ & $\boldsymbol{\theta}$ \\
\hline $\mathbf{2 9 3}$ & 61.12 & 0.6112 & 69.32 & 0.6932 & 79.8 & 0.798 & 92.31 & 0.9231 \\
$\mathbf{2 9 8}$ & 60.48 & 0.6048 & 65.59 & 0.6559 & 75.3 & 0.753 & 87.3 & 0.873 \\
$\mathbf{3 0 3}$ & 58.83 & 0.5883 & 64.27 & 0.6427 & 74.6 & 0.746 & 82.7 & 0.827 \\
$\mathbf{3 0 8}$ & 56.31 & 0.5631 & 61.82 & 0.6182 & 70.53 & 0.7053 & 78.2 & 0.782 \\
$\mathbf{3 1 3}$ & 50.36 & 0.5036 & 54.7 & 0.547 & 62.2 & 0.622 & 71.6 & 0.716 \\
\hline
\end{tabular}


The results in Table 5 confirm the previous investigations that the inhibition efficiency of the inhibitor, and the surface coverage of the metal decreased with an increase in temperature. This can be interpreted by the fact of the decrease in thermal stability of inhibitor adsorption on the metal surface with an increase in temperature. On the other hand, ionic mobility and hydrogen diffusion have a considerable role in enhancing the corrosion process. These factors are directly proportional to temperature, so they increase as the temperature increases. Meanwhile, the corrosion increases and the inhibition efficiency decreases [17].

\section{Thermodynamics of Corrosion}

\section{Inhibitor adsorption}

The inhibition mechanism is implemented through adsorption of inhibitor molecules on the metal/solution interface from the corrosive medium. The electronic density centers in these molecules play a vital role in the adsorption process. However, adsorption may occur via one of the four types of metal-inhibitor interactions: 1) the charged parts on the metal surface and inhibitor molecules interact through electrostatic attraction; 2) the donor-acceptor interactions between the metal and the uncharged electron pair that exists in the inhibitor molecules; 3 ) interaction between the metal and the $\pi$-electrons present in the inhibitor; 4) a combination of 1 and 3 [14].

\section{Thermodynamic adsorption isotherm}

The effect of concentration on the adsorption on the metal surface can be investigated through equations describing the variation of the adsorbed quantity as a function of inhibitor concentration by different adsorption models. There are a variety of adsorption models, such as Langmuir, Frumkin, Temkin, and Freundlich [18]. These models offer a linear relationship between the adsorption of inhibitor molecules on the metal surface and the inhibitor concentration. In this study, the Langmuir adsorption isotherm has been adopted because it suggests a monolayer adsorption and homogenous adsorption in which each molecule has a constant enthalpy and sorption activation energy [19]. Furthermore, the Langmuir adsorption isotherm (Equation 9) shows the best linear relationship among them, with a correlation coefficient $R^{2}$ of up to 0.996 [15].

$$
\frac{C_{\text {inh }}}{\theta}=\frac{1}{K_{\mathrm{ads}}}+C_{\mathrm{inh}}
$$

Where $C_{\text {inh }}$ and $K_{\text {ads }}$ are the inhibitor concentration and the equilibrium adsorption constant, respectively [14]. The equilibrium adsorption constant is readily calculated by plotting $\left(C_{\text {inh }} / \theta\right) v s$. $C_{\text {inh }}$, where the intercept is equal to (intercept $=1 / K_{\text {ads }}$ ), Figure 6 . 


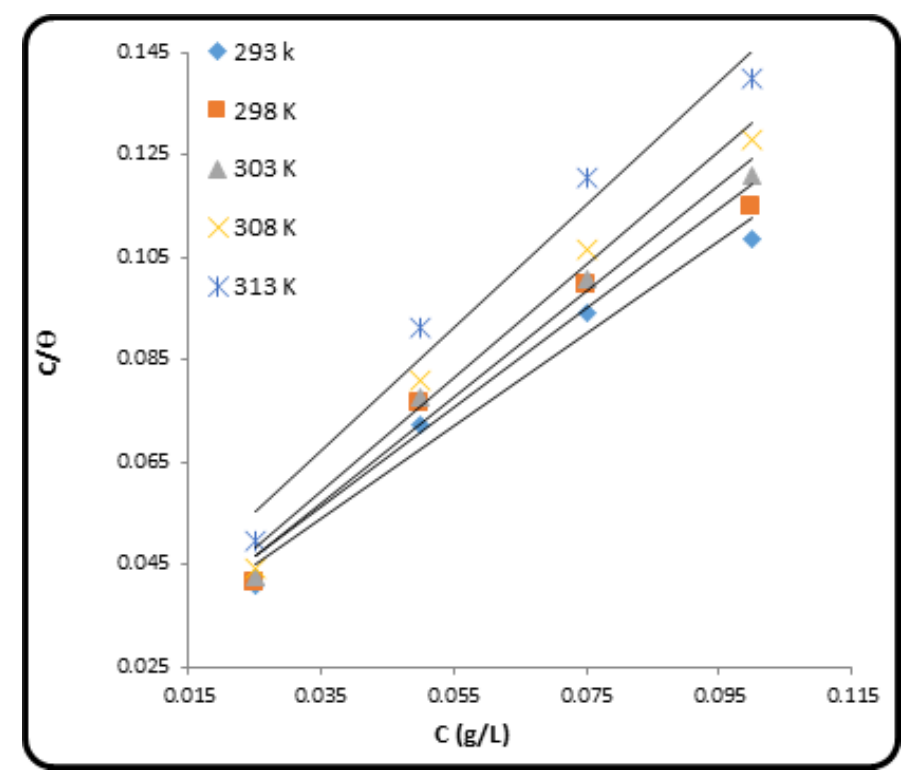

Figure 6. Langmuir adsorption isotherm plots for adsorption of different concentrations (25, 50,75 and $100 \mathrm{ppm}$ ) of HPLE on carbon steel surface in $0.5 \mathrm{M} \mathrm{HCl}$ in the temperature range of $293-313 \mathrm{~K}$.

From the intercept of the straight line with $y$ axis in the diagram above, the values of $K_{\text {ads }}$ were calculated. By introducing $K_{\text {ads }}$ values into Equation 10, the values of Gibbs free energy for adsorption $\Delta G_{\text {ads }}$ were calculated.

$$
\Delta G_{\mathrm{ads}}=-R T \ln \left(10^{3} \cdot K_{\mathrm{ads}}\right)
$$

Where 1000 denotes the water concentration in $\mathrm{g} / \mathrm{L}, R$ is the universal gas constant $(8.34 \mathrm{~J} / \mathrm{mol} \cdot \mathrm{K})$, and $T$ is the temperature in Kelvin degrees [20].

In practice, it's relatively difficult to classify the adsorption of inhibitor molecules as a purely physical or purely chemical phenomenon. This is because chemical adsorption is typically paired with physical adsorption via charge interactions between two charged centers on the inhibitor molecules and the metal surface [21]. Through the values of Gibbs free energy $\left(\Delta G_{\text {ads }}\right)$, it can be ranked as an adsorption process, whether physical or chemical adsorption.

When $\Delta G_{\text {ads }}=-20 \mathrm{~kJ} / \mathrm{mol}$ or less negative, adsorption occurs through charge interactions between the metal surface and inhibitor molecules, and physical adsorption predominates (physisorption).

In contrast, when $\Delta G_{\mathrm{ads}}=-40 \mathrm{~kJ} / \mathrm{mol}$ or more negative, adsorption occurs via donoracceptor interactions (charge transfer) between the metal surface and the inhibitor molecules, and chemical adsorption (chemisorption) predominates [17].

The enthalpy of adsorption $\Delta H_{\text {ads }}$ and the entropy of adsorption $\Delta S_{\text {ads }}$ are evaluated by the Gibbs Equation:

$$
\Delta G_{\mathrm{ads}}=\Delta H_{\mathrm{ads}}-T \cdot \Delta S_{\mathrm{ads}}
$$


Through a plot of $\Delta G_{\text {ads }} v s$. temperature $T$, the enthalpy $\Delta H_{\text {ads }}$ is represented by the intercept of the straight line with the $y$ axis while the slope is the entropy $\Delta S_{\text {ads }}$ [22] (Figure 7).

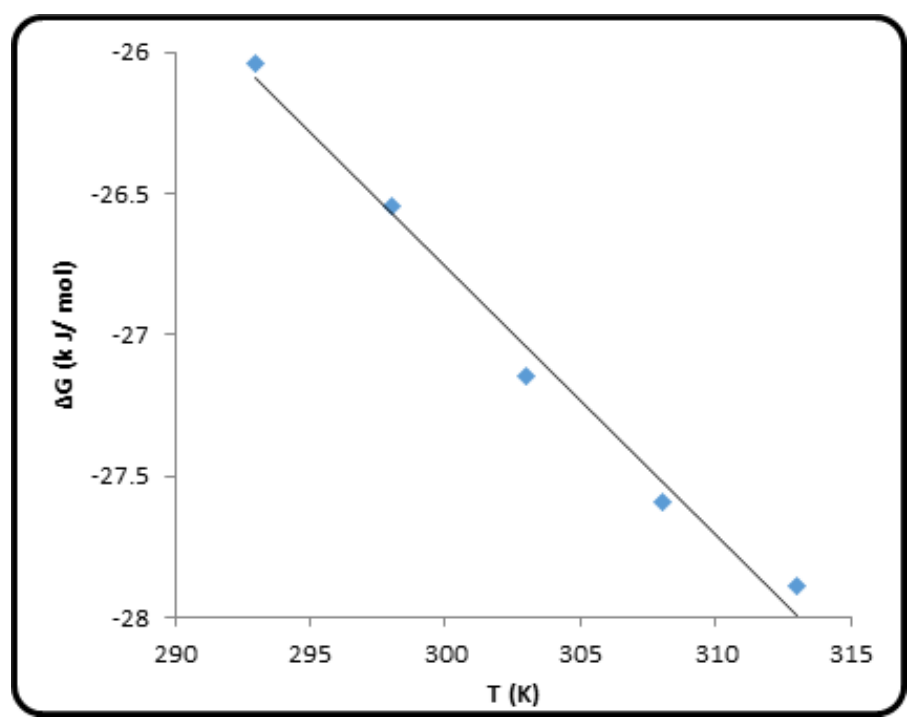

Figure 7. Plot of Gibbs free energy vs. temperature for adsorption of different concentrations $(25,50,75$ and $100 \mathrm{ppm})$ of HPLE on carbon steel surface in $0.5 \mathrm{M} \mathrm{HCl}$ in the temperature range of $293-313 \mathrm{~K}$.

All adsorption thermodynamic parameters are listed in Table 6 . From the $\Delta G_{\text {ads }}$ values in this table, it can be concluded that the adsorption process is spontaneous and within the range of physical adsorption.

Table 6. Adsorption thermodynamic parameters for adsorption of different concentrations (25, 50, 75 and $100 \mathrm{ppm}$ ) of HPLE on carbon steel surface in $0.5 \mathrm{M} \mathrm{HCl}$ in the temperature range of 293-313 K.

\begin{tabular}{ccccc}
\hline $\boldsymbol{T}(\mathbf{K})$ & $\boldsymbol{K}_{\text {ads }}\left(\mathbf{g}^{-\mathbf{1}} \cdot \mathbf{L}\right)$ & $\Delta \boldsymbol{G}_{\text {ads }}\left(\mathbf{k J} \cdot \mathbf{m o l}^{\mathbf{1}}\right)$ & $\boldsymbol{\Delta} \boldsymbol{H}_{\text {ads }}\left(\mathbf{k J} \cdot \mathbf{m o l}^{\mathbf{1}}\right)$ & $-\boldsymbol{S}_{\text {ads }}\left(\mathbf{J} \cdot \mathbf{m o l}^{\left.\mathbf{1} \cdot \mathbf{K}^{\mathbf{1}}\right)}\right.$ \\
\hline 293 & 43.85965 & 26.0378 & & \\
298 & 45.05050 & 26.5482 & & \\
303 & 47.84689 & 27.1457 & 2.624 & \\
308 & 47.84689 & 27.5936 & & \\
313 & 47.65451 & 27.8910 & & \\
\hline
\end{tabular}

As it has been seen in the table above, the values of Gibbs energy were in the physical adsorption range, and they became more negative with an increase in temperature. Also, the negative sign of enthalpy indicates that the inhibitor adsorption is an exothermic process [23]. On the other hand, the positive sign of entropy refers to an increase in randomness; this may be attributed to the replacement of water molecules by inhibitor molecules, which leads to an increase in disorder and, consequently, entropy [24]. 


\section{Scanning electron microscopy (SEM)}

A metal surface morphology test was performed by scanning electron microscopy (SEM) technique. Figure 8 shows the surface morphology images of carbon steel samples before and after soaking in $0.5 \mathrm{M} \mathrm{HCl}$ solutions for $24 \mathrm{~h}$ at room temperature in the absence and presence of HPLE. In Figure 8-a, a polished CS sample is shown that is flat without any pits or appearances of corrosion. Figure 8-b shows the image topography of a CS sample after being immersed in an uninhibited solution. It is evident from this picture that the pits and cavities are appreciable on the metal surface. In Figure 8-c, an image of the topography of a CS sample after being immersed in an inhibited solution, it is obvious that inhibitor molecules have been adsorbed on the CS surface and the protective film was formed to act as a physical barrier between the metal surface and the environment.

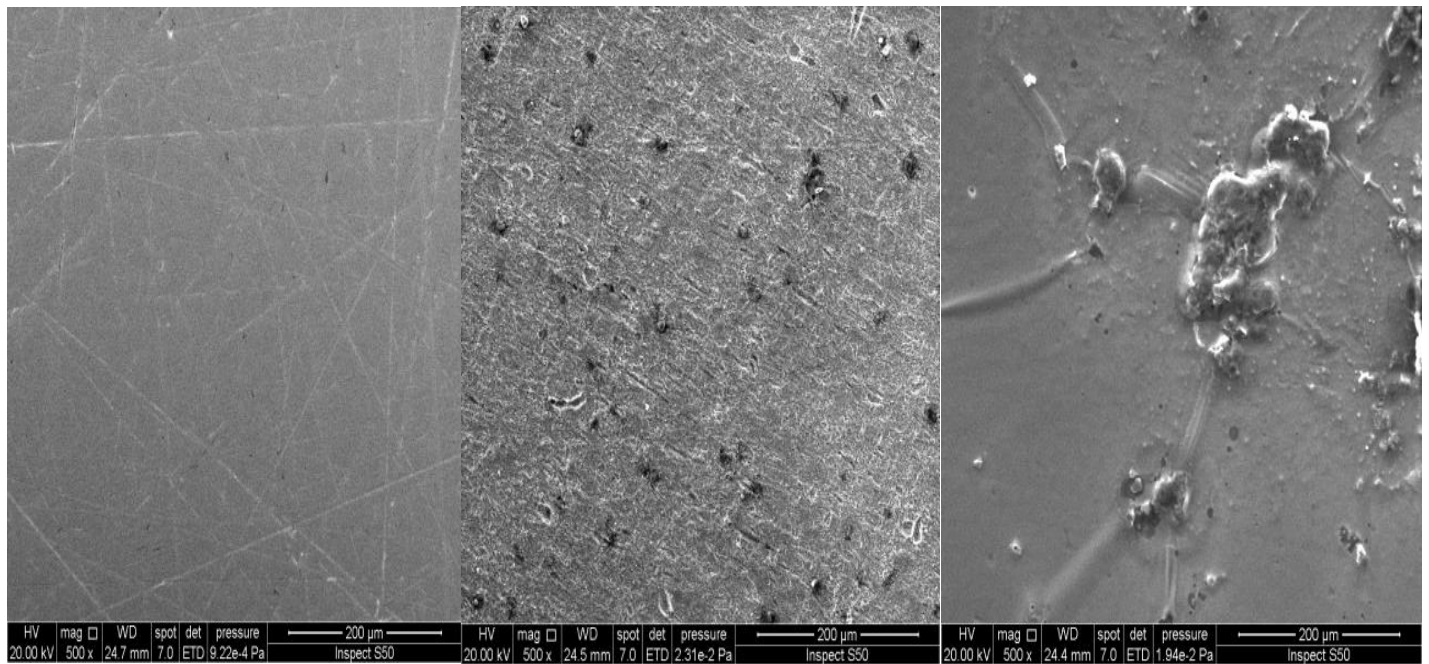

(a)

(b)

(c)

Figure 8. SEM micrographs of carbon steel: a) polished specimen; b) after immersion in aggressive $0.5 \mathrm{M} \mathrm{HCl}$ for $24 \mathrm{~h}$ at r.t.; c) the same conditions as in (b) in the presence of 100 ppm HPLE inhibitor.

\section{Energy Dispersive X-ray spectroscopy (EDX)}

EDX analysis was accomplished in order to identify the assortment of elements on the metal surface for three samples in different states, i.e., (a) polished dry specimen; (b) specimen after immersion in $0.5 \mathrm{M} \mathrm{HCl}$ for $24 \mathrm{~h}$; and (c) the same conditions as in (b) in the presence of 100 ppm HPLE inhibitor.

As it is obvious from Figure 9, the peaks of $\mathrm{Cl}$ and $\mathrm{O}$ appear in the blank solution, Figure 9b, while they are absent in Figure 9a, which indicates the rust formation on the metal surface. Also in Figure 9c, there is a decrease in the $\mathrm{Cl}$ and $\mathrm{O}$ peaks in comparison with Figure $b$, which indicates a decrease in the corrosion process. 
Furthermore, the appearance of $N$ and $S$ peaks in Figure c refers to the presence of HPLE molecules adsorbed on the MS [25]. The mass element ratios obtained from the EDX spectra are listed in Table 7.

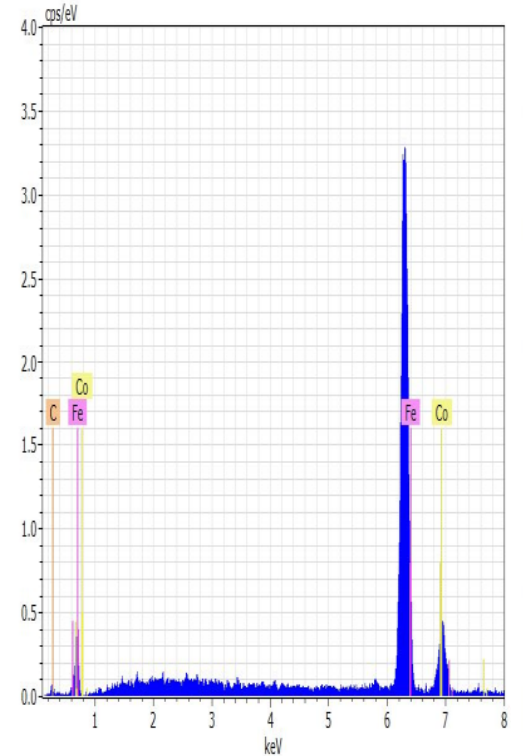

(a)

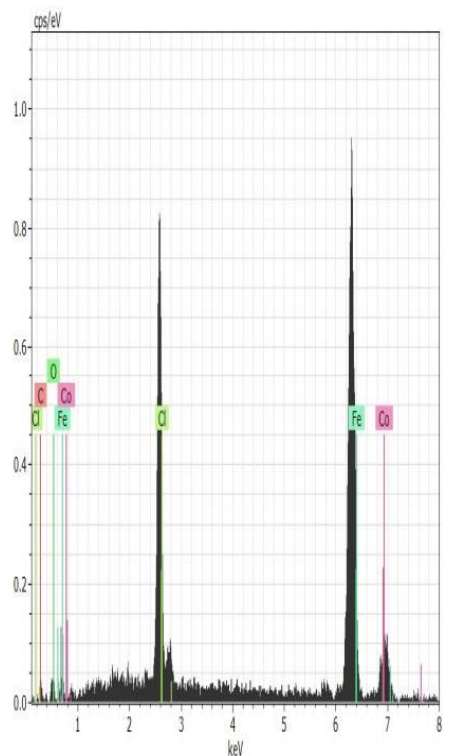

(b)

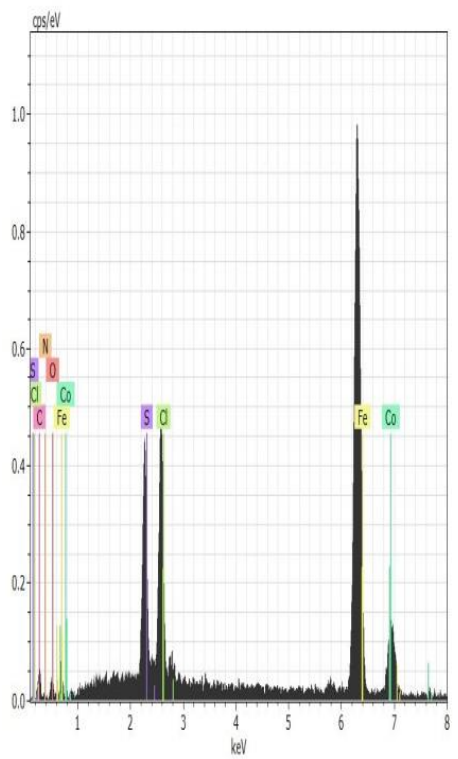

(c)

Figure 9. EDX spectrum of carbon steel: a) polished specimen; b) after immersion in aggressive $0.5 \mathrm{M} \mathrm{HCl}$ for $24 \mathrm{~h}$ at r.t.; c) the same conditions as in (b) in the presence of 100 ppm HPLE inhibitor.

Table 7. The wt.\% of the elements in the EDX spectrum.

\begin{tabular}{cccccccc}
\hline \multirow{2}{*}{ Figure } & \multicolumn{7}{c}{ Element Percentage in wt.\% } \\
\cline { 2 - 7 } & Fe & Co & C & Cl & O & S & N \\
\hline Figure 9-a & 74.28 & 22.06 & 3.66 & - & - & - & - \\
Figure 9-b & 44.95 & 12.56 & 4.19 & 35.24 & 3.06 & - & - \\
Figure 9-c & 41.53 & 13.09 & 7.33 & 18.82 & 2.01 & 14.69 & 2.53 \\
\hline
\end{tabular}

\section{Conclusion}

In this study, the pomelo leaves were extracted with n-hexane by the maceration extraction method. The chemicals in crude extract were diagnosed by GC-MS and FTIR spectroscopy. Esters are considered the most important among several organic compounds that exist in this extract. Afterward, the HPLE was investigated as a corrosion inhibitor for CS in $0.5 \mathrm{M} \mathrm{HCl}$ in the temperature range of 293-313 K. Four concentrations $(25,50,75$, and $100 \mathrm{ppm})$ of this extract were utilized for CS corrosion studies. Potentiodynamic polarization curves indicate that HPLE is a mixed-type inhibitor and that it shows a prominent anti-corrosion performance of up to $82.32 \%$ at $100 \mathrm{ppm}$ concentration. The mechanism of inhibition 
operates through adsorption of HPLE molecules on the metal surface. This adsorption is compatible with the Langmuir adsorption isotherm and occurs fundamentally as physical adsorption. The calculated Gibbs energy indicates that the adsorption process occurs spontaneously. In addition, surface morphology (SEM) and element composition of the metal surface (EDX) tests confirm the formation of a protective film on the metal surface by adsorption of inhibitor molecules.

\section{References}

1. L. Yang, Techniques for Corrosion Monitoring, Second Edition, Woodhead Publishing, Elsevier, United Kingdom, 2020, p. 7.

2. J.K. Chen and J.P. Thyssen, Metal Allergy: From Dermatitis to Implant and Device Failure, Springer, 2018, p. 17. doi: 10.1007/978-3-319-58503-1

3. Inamuddin, M.I. Ahmed, R. Boddula and M. Luqman, Theory and Applications of Green Corrosion Inhibitors, Materials Research Forum LLC, USA, 2021, p. 3.

4. S. Marzorati, L. Verotta, and S.P. Trasatti, Green Corrosion Inhibitors from Natural Sources and Biomass Wastes, Molecules, 2019, 24, 1-24. doi: 10.3390/molecules24010048

5. A. Miralrio and A.E. Vázquez, Plant Extracts as Green Corrosion Inhibitors for Different Metal Surfaces and Corrosive Media: A Review, Processes, 2020, 8, 1-27. doi: 10.3390/pr8080942

6. S. Satpati, S.Kr. Saha, A. Suhasaria, P. Banerjee and D. Sukul, Adsorption and anticorrosion characteristics of vanillin Schiff bases on mild steel in $1 \mathrm{M} \mathrm{HCl}$ : experimental and theoretical study, $R S C A d v$., 2020, 10, 9258-9273. doi: 10.1039/c9ra07982c

7. A.B.D. Nandiyanto, R. Oktiani and R. Ragadhita, How to Read and Interpret FTIR Spectroscope of Organic Material, J. Sci. Technol., 2019, 4, 97-118. doi: 10.17509/ijost.v4i1.15806

8. A.A. Ganash, Comparative Evaluation of Anticorrosive Properties of Mahaleb Seed Extract on Carbon Steel in Two Acidic Solutions, Materials, 2019, 12, 3013. doi: 10.3390/ma12183013

9. A.R. Polu and R. Kumar, Impedance Spectroscopy and FTIR Studies of PEG-Based Polymer Electrolytes, E-J. Chem., 2011, 8, 347-353. doi: 10.1155/2011/628790

10. R.S.A. Hameed, M.M. Aljohani, A.B. Essa, A. Khaled, Amr.M. Nassar, M.M. Badr, S.R. Al-Mhyawi and M.S. Soliman, Electrochemical Techniques for Evaluation of Expired Megavit Drugs as Corrosion Inhibitor for Steel in Hydrochloric Acid, Int. J. Electrochem. Sci., 2021, 16, 210446. doi: 10.20964/2021.04.15

11. Y. Liu, Zh. Gao, X. Lu and L. Wang, Effect of Temperature on Corrosion and Cathodic Protection of X65 Pipeline Steel in 3.5\% NaCl Solution, Int. J. Electrochem. Sci., 2019, 14, 150-160. doi: $10.20964 / 2019.01 .54$

12. M.M. Li, Qun-Jie Xu, J.H.H. Yun and Yu. Min, Inhibition Action and Adsorption Behavior of Green Inhibitor Sodium Carboxymethyl Cellulose on Copper, Int. J. Electrochem. Sci., 2015, 10, 9028-9041. 
13. A.B. Mohammed and T.A. Salman, Corrosion Inhibition of Carbon Steel in Saline Solution Using Amino Acids, Int. J. Pharm. Sci. Rev., 2019, 40, 182-190. https://www.researchgate.net/publication/333982491

14. Y. El Kacimi, S. Kaya, R. Touir, New Challenges and Industrial Applications for Corrosion Prevention and Control, IGI Global, USA, 2020, p. 104.

15. M. Aliofkhazraei, Intermetallic Compounds: Formation and Applications, BoD - Books on Demand, United Kingdom, 2018, p. 213.

16. H.M. Abd El-Lateef, M. Ismael and I.M.A. Mohamed, Novel Schiff base amino acid as corrosion inhibitors for carbon steel in $\mathrm{CO}_{2}$-saturated $3.5 \% \mathrm{NaCl}$ solution: experimental and computational study, Corros. Rev., 2015, 33, 77-97. doi: 10.1515/corrrev-2014-0059

17. T.A. Salman, Q.A. Jawad, M.A.M. Hussain, A.A. Al-Amiery and L.M. Shaker, Abdul A.H. Kadhum and M.S. Takriff, Cogent Engineering, New environmental friendly corrosion inhibitor of mild steel in hydrochloric acid solution: Adsorption and thermal studies, Cogent Engineering, 2020, 7, 1-17. doi: 10.1080/23311916.2020.1826077

18. R.A. Hamza, K.A. Samawi and T. Salman, Inhibition Studies of Aluminium alloy Corrosion in Acid Hydrochloride Solution Using an Expired Phenylphrine Drug, Egyptian J. Chem., 2020, 63, 2863-2875. doi: 10.21608/EJCHEM.2020 .19583.2222

19. A. Al-Amiery, T. Salman, Kh. Alazawi, L. Shaker, Ab. Kadhum and M. Takriff., Quantum chemical elucidation on corrosion inhibition efficiency of Schiff base: DFT investigations supported by weight loss and SEM techniques, Int. J. Low-Carbon Technol., 2020, 15, 202-209. doi: 10.1093/ijlct/ctz074

20. T.A. Salman, A.A. Al-Amiery, L.M. Shaker, A.A.H. Kadhum and M.S. Takriff, A study on the inhibition of mild steel corrosion in hydrochloric acid environment by 4 methyl-2-(pyridin-3-yl)thiazole-5-carbohydrazide, Int. J. Corros. Scale Inhib., 2019, 8, no. 4, 1035-1059. doi: 10.17675/2305-6894-2019-8-4-14

21. M.A. Hegazy., Novel cationic surfactant based on triazole as a corrosion inhibitor for carbon steel in phosphoric acid produced by dihydrate wet process, J. Mol. Liq., 2015, 208, 227-236. doi: 10.1016/j.molliq.2015.04.042

22. M. Yadav, L. Gope, N. Kumari and P. Yadav, Corrosion inhibition performance of pyranopyrazole derivatives for mild steel in $\mathrm{HCl}$ solution: Gravimetric, electrochemical and DFT studies, J. Mol. Liq., 2016, 216, 78-86. doi: 10.1016/j.molliq.2015.12.106

23. C.A.C. Sequeira, High Temperature Corrosion: Fundamentals and Engineering, John Wiley \& Sons, USA, 2018, p. 209.

24. S.T. Hameed, T.A. Salman and S.F. Al-Saidi, The Inhibition Effect of Ampicillin on Corrosion of Pure Aluminium in $3.5 \% \mathrm{NaCl}$ Aqueous Solution, J. Al-Nahrain University, 2015, 18, 50-61. doi: 10.22401/JNUS.18.3.08

25. T.A. Salaman and H.M. Raheem, Electrophoresis Deposition of Tungsten Oxide Nanoparticles for Corrosion Inhibition, J. Phys.: Conf. Ser., 2020, 1664, 012053. doi: $\underline{10.1088 / 1742-6596 / 1664 / 1 / 012053}$ 